\section{(6) OPEN ACCESS}

\title{
Withdrawal of ventilatory support outside the intensive care unit: guidance for practice
}

\author{
Joanna Laddie, ${ }^{1}$ Finella Craig, ${ }^{2}$ Joe Brierley, ${ }^{3}$ Paula Kelly, ${ }^{4}$ Myra Bluebond-Langner ${ }^{5,6}$
}

${ }^{1}$ Evelina London Children's Hospital, Guys and

St Thomas's NHS Foundation Trust, London, UK

${ }^{2}$ The Louis Dundas Centre for Children's Palliative Care, Great Ormond Street Children's Hospital NHS Foundation Trust, London, UK

${ }^{3}$ Great Ormond Street Children's Hospital NHS

Foundation Trust, London, UK

${ }^{4}$ The Louis Dundas Centre for Children's Palliative Care, University College London, Institute of Child Health and Lecturer in Child and Adolescent Nursing, Kings College London, London, UK. ${ }^{5}$ The Louis Dundas Centre for Children's Palliative Care, University College London, Institute of Child Health, London, UK

${ }^{6}$ Rutgers University, Camden, New Jersey, USA

\section{Correspondence to} Dr Joanna Laddie, Evelina London Children's Hospital, Westminster Bridge Road, London SE1 7EH, UK; Joanna.Laddie@gstt.nhs.uk

Received 21 October 2013 Revised 21 April 2014 Accepted 1 June 2014 Published Online First 20 June 2014

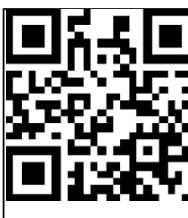

\section{SLinked}

- http://dx.doi.org/10.1136/ archdischild-2014-306417

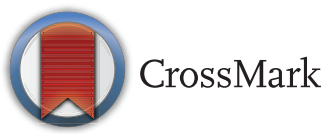

To cite: Laddie J, Craig F, Brierley J, et al. Arch Dis Child 2014;99:812-816.

\section{ABSTRACT}

Objective To review the work of one tertiary paediatric palliative care service in facilitating planned withdrawal of ventilatory support outside the intensive care setting, with the purpose of developing local guidance for practice.

Methods Retrospective 10-year (2003-2012) case note review of intensive care patients whose parents elected to withdraw ventilation in another setting. Demographic and clinical data revealed common themes and specific incidents relevant to local guideline development. Results 18 children (aged 2 weeks to 16 years) were considered. Three died prior to transfer. Transfer locations included home (5), hospice (8) and other (2). Primary pathologies included malignant, neurological, renal and respiratory diseases. Collaborative working was evidenced in the review including multidisciplinary team meetings with the palliative care team prior to discharge. Planning included development of symptom management plans and emergency care plans in the event of longer than anticipated survival. Transfer of children and management of extubations demonstrated the benefits of planning and recognition that unexpected events occur despite detailed planning. We identified the need for local written guidance supporting healthcare professionals planning and undertaking extubation outside the intensive care setting, addressing the following phases: (i) introduction of withdrawal, (ii) preparation pretransfer, (iii) extubation, (iv) care postextubation and (v) care postdeath. Conclusions Planned withdrawal of ventilatory support outside the intensive care setting is challenging and resource intensive. The development of local collaborations and guidance can enable parents of children dependent on intensive care to consider a preferred place of death for their child, which may be outside the intensive care unit.

\section{INTRODUCTION}

Admission to the aggressive and invasive treatment environment of the intensive care unit (ICU) may follow from the first episode of a life-threatening illness or following deterioration or concurrent illness in a child with an underlying life-limiting condition. $^{1-4}$ Treatment is aimed at cure or restoration of the child or neonate to a more stable health state. Despite improvements in outcomes for children admitted to ICUs, there are cohorts of children who cannot be cured or have their physiological derangement reversed to an acceptable level. $^{15-7}$ In these cases, continuation of IC may be decided as no longer in the child's best interest and planning is required for withdrawal or withholding of further invasive IC therapy. ${ }^{8-10}$

Traditional practice has been to stop invasive treatment on ICU and for children to receive

\section{What is already known on this topic?}

The majority of children who die in the hospital setting do so in an intensive care environment.

- The integration of palliative care with intensive care can reduce the burden of invasive interventions and increase out-of-hospital deaths.

- The withdrawal or withholding of intensive therapy places professional, ethical and legal obligations on clinicians.

\section{What this study adds?}

- Planning can enable parents of children dependent on intensive care to choose a place of death outside the hospital for their child.

- Identifies the resources, knowledge and skills required to facilitate withdrawal of ventilatory support outside the hospital setting for children at the end of life.

end-of-life care and die in the ICU. ${ }^{11-14} \mathrm{~A}$ small number of centres have reported transfer outside ICU for withdrawal, with evidence suggesting many families prefer their dying child to go home. ${ }^{15-19}$ The provision of choice in place of care, and subsequently of death, for children is increasingly advocated. ${ }^{20-22}$

In this paper, we report on the experiences of one specialist paediatric palliative care (PPC) team in a tertiary hospital collaborating with four different hospital's ICU services in conducting out-of-hospital extubations. We report on the challenges such discharges present, including the practical, logistical and legal considerations that must be addressed. We outline a process to facilitate extubations outside of the IC setting for children with life-threatening illnesses.

The PPC service cares for children with malignant and non-malignant life-threatening or lifelimiting conditions within hospital and community settings. ${ }^{23-25}$ Collaborative working between the $\mathrm{ICU}^{26}$ and PPC service includes supporting care within the paediatric ICU (PICU) setting as well as following discharge. ${ }^{27-29}$

\section{METHODS}

We conducted a retrospective case note review of children and young people referred to our PPC 
service from ICU for withdrawal of life-sustaining therapy (LST). Following the registration of the review with the audit department (audit registration number 776), we used the palliative care service database to identify the patient group for audit. The inclusion criterion was any ICU referral (from within our trust and other external ICUs in our catchment area) between 2003 and 2012 where withdrawal of LST occurred outside hospital. LST was defined for this review as intubation and receiving positive pressure ventilation via an endotracheal tube.

Electronic and paper notes from both the PPC service and ICU within our own trust were reviewed retrospectively (by JL). Background demographic information was extracted, including ages, gender and diagnoses. Narrative text within the notes was examined to provide a comprehensive description of the actual process of out of ICU withdrawal of LST. These descriptions were analysed by JL to identify unique and common issues across the data set.

\section{RESULTS}

\section{Characteristics of identified cases}

In total, 18 children were identified in the last 10 years (20032012) for whom out-of-hospital withdrawal of LST was planned. Of these, 12 were referred from within our trust and 6 from 3 other ICUs providing care to children and or neonates. All cases involved withdrawal of invasive mechanical ventilation and some also involved cessation of inotropic circulatory support. Also, 3 of the 18 children were extubated prior to transfer and thus have been excluded from the analysis. The remaining 15 cases ranged from 2 weeks to 16 years of age and comprised 9 boys and 6 girls. Eleven were referred from PICU and four from the neonatal ICU (NICU) (figure 1). Prior to transfer, six patients had documented unsuccessful trials of extubation on the ICU. One child was lost to follow-up (transferred out of area).

The primary diagnoses of the children varied; the majority having neurological, renal or respiratory primary diagnoses. All had multisystem pathologies. Two children were known to the PPC service before admission to the ICU. The time from ICU admission to PPC referral ranged from 4 to 30 days (mean $=13.3$ days). The time from ICU admission until transfer out ranged from 3 to 50 days (mean=14.1 days). The time to transfer out following referral to the PPC team (on this admission) ranged from 0 to 10 days (mean $=2$ days).

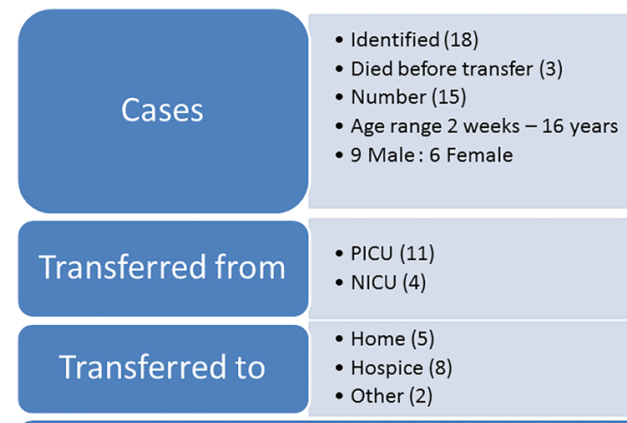

Collaboration between palliative services and 4 ICUs

Figure 1 Characteristics of cases extubated outside of intensive care unit (ICU) 2003-2012 ( $n=15)$.

\section{Collaborative working}

Following referral to the PPC team, a multidisciplinary team (MDT) meeting was documented to have occurred in six cases pretransfer. All MDT meetings included the parents $( \pm$ other family members), ICU physicians and PPC physicians. Four also included physicians from the primary speciality and two included the PICU liaison nurse. General practitioners (GP), children's community nursing teams (CCNT) and hospice staff were not documented to have been present at any of the MDT meetings.

The child's GP was contacted prior to transfer in nine cases and the CCNT contacted in five cases. Local hospices were contacted only if the child was to be transferred there. We found no evidence of prior contact with local paediatricians or local coroners, which was identified as problematic in one case.

Information concerning the number, nature and timing of conversations with parents was unclear. Notes showed that first discussion of out-of-hospital withdrawal of LST was sometimes initiated by ICU staff and sometimes by PPC staff. In no cases was it documented that the families initiated the discussions. The preparation of documents such as Emergency Care Plans (ECP) outlining parents' wishes for further interventions should their child survive longer than expected following withdrawal of LST and documented 'Do Not Attempt Resuscitation' (DNAR) orders for some children suggested a range of discussions with parents.

\section{Symptom management}

We identified evidence of considerable planning to maintain the child's stability and comfort during transfer, immediately prior to and postextubation. Provision was also made for ongoing symptom management for children who survived the immediate postextubation period (figure 2). This included management of pain, agitation and dyspnoea (including the supply of home oxygen in three cases); fluid management and maintenance of cardiovascular stability. Medications were required in formulations that could be administered via existing routes, such as infusions, and alternative routes (buccal, oral, rectal, transcutaneous), according to the child's condition or the setting.

\section{The transfer}

Pretransfer planning aimed to ensure all medications and equipment were available and usable in the destination setting and that buildings were accessible with equipment, although this was not always comprehensively documented.

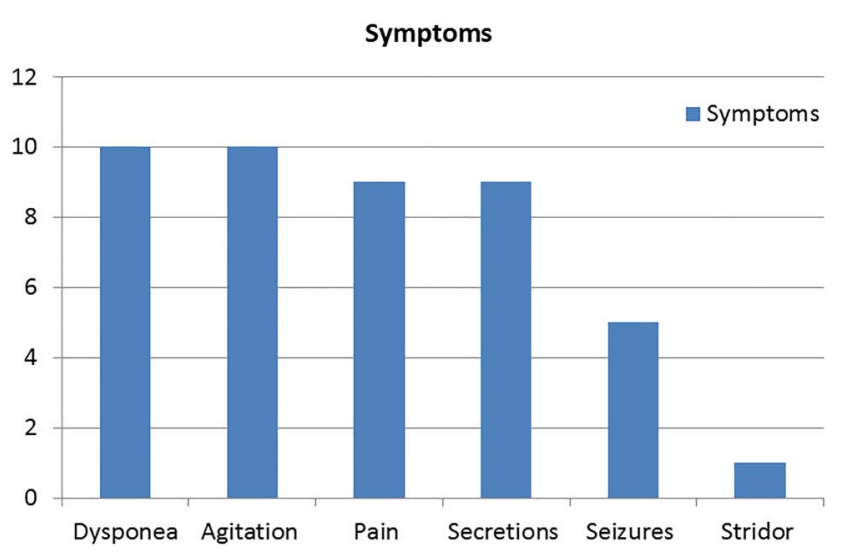

Figure 2 Symptoms anticipated following withdrawal of life-sustaining therapy (LST) documented on symptom management plans. 
At the time of transfer, all patients had been assessed by a member of the PPC team and all transfers were accompanied by two ICU staff members (ICU physician and nurse or two nurses). All families were offered the option of a family member travelling in the ambulance with the child and some elected not to. In 11 cases, the child was met at the destination by a member of the PPC team ( 2 by a PPC nurse and 9 by a physician) and in 1 case a GP also attended.

\section{Extubation}

At the time of withdrawal of LST, all patients had their families present. Time until death following withdrawal of LST ranged from 'immediate' to 5 days. Of note, 12 patients died within $13 \mathrm{~h}$ with only 4 of these surviving beyond $2 \mathrm{~h}$. One child survived postextubation and was later discharged from specialist palliative care services.

Unexpected and unanticipated signs of life following withdrawal of life-sustaining ventilatory support were documented as distressing for some parents.

There were no reported major complications, such as unanticipated symptoms.

There was limited documentation with regards to completion of death certificates. These were completed on three occasions by staff from our trust, in two cases by the GP and in one case by the receiving doctor at another trust. There was no record of who completed the remaining eight.

\section{DISCUSSION}

This project provides additional evidence ${ }^{15-19}$ that extubation outside the IC setting is feasible, expanding the choice in place of death for IC patients. ${ }^{28-31}$ However, preparing for and undertaking this care strategy is resource intensive and requires significant collaboration between healthcare teams, to ensure clinical and emotional safety for children, parents and professionals. Based on our review and experience, we have developed general guidance addressing the five phases of extubation outside the IC setting: (i) introduction of withdrawal, (ii) preparation pretransfer, (iii) extubation, (iv) care postextubation and (v) care postdeath. The guidance aims to help professionals maintain discussion with parents, ensure continuity of care and provide comprehensive support external to the IC setting.

\section{Introduction of withdrawal}

Introducing the option for withdrawal of LST outside the IC setting requires IC and PPC staff to balance the potential extension of a child's suffering with the need to compassionately provide parents with complex information, 2232 to enable informed contribution to decision making. PICU's report wide variations in timelines for end-of-life decision making. ${ }^{10}$ The decision for out-of-hospital extubation often means that parents will be working with a new team of professionals. Only two families already knew the PPC team and five children were referred from a different hospital. The sense of continuity of care for the family must be maintained, while rapidly coordinating additional services, in the face of the child's potential for acute deterioration. ${ }^{17} 182134$

\section{Preparation pretransfer}

Preparation pretransfer should include engaging with a range of professionals, including GPs, CCNTs, local paediatricians, PPC team, IC staff, emergency services and the coroners' office. In our experience, the timescales required to achieve timely discharge do not usually allow local hospital, hospice or community staff to be present at an MDT meeting with parents on the
ICU. Hence, detailed conversations, written guidance and agreement of responsibilities must be at the core of planning and coordination with local services.

In addition to discussions among professionals, preparation pretransfer should include discussions with parents about which family members they would like present as well as any personal or religious rituals (eg, blessings) they would like performed before withdrawal. ${ }^{13}{ }^{17}$ These conversations also provide an opportunity to talk with the parents about care after death, including the use of tranquil suites in children's hospices for the child's body, regardless of place of death.

Each team needs to consider the staffing and equipment required to provide support for extubation outside the ICU, anticipating that the time from extubation to the child's death is uncertain. Accessibility of equipment at the destination is crucial, and parents and local staff can provide key practical knowledge in this.

The postextubation period requires management of ongoing symptoms. There needs to be clear agreement which professional will be responsible for managing this phase of care. ${ }^{35}$

Attention must be given to the legal procedures that accompany death (confirmation and death certification together with completion of cremation forms). Requirements with regards to medical certification of the cause of death (MCCD) and cremation forms mean it is essential to plan ahead prior to a child's death, including coronial consideration. ${ }^{32} 36$ Our experience indicates that informing those responsible for the legal and registration aspects of death (including the coroner) in a timely manner prevents unnecessary and distressing delays for families after the child's death.

There also needs to be clarity about which service will take responsibility for ensuring the family have access to bereavement services. This will prevent duplication or omission of bereavement care.

\section{Extubation}

Extubation should be carried out in accordance with parameters discussed and agreed by members of the MDT and family pretransfer. The withdrawal of LST other than ventilation and initiation of interventions to control symptoms should always be planned for and carried out according to the assessed need of the individual child. Drugs should be available in case of rapid symptom progression.

Parents may require ongoing explanations of potential and actual symptoms the child may experience including how these are/will be managed as the extubation proceeds.

Immediately following extubation the professionals present need to maintain a careful balance between providing families with privacy and being sufficiently available to reduce anxiety. This may be particularly challenging for families whose recent experience in IC has involved the constant presence of healthcare professionals.

\section{Care postextubation}

Guidance and support in the management of symptoms with both pharmacological and non-pharmacological agents must be clear and prompt with attention to a plan for feeding and fluids. ECP should be reviewed to ensure they are in keeping with the family's wishes and to ensure all members of the MDT are aware of the family's wishes and decisions. All members of the team and the family should hold a copy.

Parents need to be aware of who to contact should the child survive longer than expected, as well as who to contact and when postdeath. 


\section{Care postdeath}

Of particular importance after death will be care of the child's body, their family and potentially their community. Attention should be given to the family's cultural practices and spiritual beliefs. GPs and community staff often have more detailed local knowledge to contribute. Legal paperwork needs to be completed promptly and be consistent with family's wishes regarding cultural and religious practices. Identification of bereavement support should again be clarified. Time should also be given to staff reflection and debriefing. ${ }^{19}$ Debriefs can provide an opportunity not only to reflect on a particular case, but also to inform the development of practice. In our trust, we use the monthly morbidity and mortality meetings held in the IC to review cases. All staff can access confidential supervision.

We have outlined our local guidance based on this review and our experiences as a tertiary centre (table 1 ) recommending action required for an out-of-hospital withdrawal of LST. This includes ensuring adequate symptom management, continuity of family support and professional engagement. Adapting this guidance to suit local circumstances and resources as well as developing (for each potential patient) a checklist, placed in the notes to aid planning, preparation, implementation and debrief, is recommended. ${ }^{19}$

\section{Limitations}

The available databases did not allow identification of all children/families for whom out-of-hospital extubation was offered but did not occur. In addition, the total number of patients identified is small and they have a very diverse disease profile. Information was gathered through reviewing notes, including notes from two different departments (both paper and electronic), and we identified cases with incomplete or minimal detail recorded. A retrospective audit of medical notes cannot provide an adequate account of medical decision making in these circumstances. ${ }^{10}$ We have no direct data on the parents' perspectives.

\section{CONCLUSIONS}

Meticulous planning and communication with families and professionals is essential for facilitating out-of-hospital withdrawals of LST. We recommend early involvement of a palliative care team.

Once the decision to withdraw is made, plans must be quickly communicated and implemented. Transfer and extubation should adhere to a mutually agreed time line. Survival postwithdrawal is variable and must be planned for.

Table 1 Guidance for hospital staff planning extubations outside intensive care (IC) settings (following clinical judgement that IC interventions are deemed to be futile and not in the child's best interest)

\begin{tabular}{|c|c|}
\hline Phase of care & Actions to be taken \\
\hline $\begin{array}{l}\text { Introduction of } \\
\text { withdrawal }\end{array}$ & $\begin{array}{l}\text { Consult with palliative care service } \\
\text { Identify appropriate clinicians to meet with parents to discuss management of child's care and treatment } \\
\text { Meet with parents to discuss withdrawal including Implications of withdrawal Management of symptoms Place of care preferences Provide parents } \\
\text { with opportunities for further discussions and involvement in decision making }\end{array}$ \\
\hline Pre transfer & $\begin{array}{l}\text { Rationalise medication and interventions to maximise comfort } \\
\text { Contact religious/spiritual advisors as per family wishes } \\
\text { Identify and contact appropriate local services Home-general practitioner, community children's nursing team, local paediatrician Hospice-lead } \\
\text { nurse and designated medical support Local hospital-lead consultant } \\
\text { Negotiate availability of local services to meet child and family at home, or support extubation at destination } \\
\text { Negotiate availability of ambulance services for transfer } \\
\text { Acquire knowledge on accessibility at planned destination from parents, family members and or local staff } \\
\text { Ensure destination is accessible for all equipment } \\
\text { Ensure necessary equipment necessary for transfer and ongoing care available and able to be used in required settings Ensure arrangements in } \\
\text { place for certification postdeath } \\
\text { Review with family agreed time frame for extubation } \\
\text { Distribute Symptom Management Plan (SMP) to all members of the local, transferring team and destination team and give a copy to the family } \\
\text { Arrange medication recommended in SMP to be available at transfer site } \\
\text { Train parents/carers in how to give potential ongoing medication } \\
\text { Discuss and agree planned action if extubation or death occurs during transfer } \\
\text { Establish which health professionals will carry out extubation } \\
\text { Determine timescale for discontinuation of life-dependent medications (ie, in the ICU, on arrival at the destination or peri-extubation) }\end{array}$ \\
\hline Extubation & $\begin{array}{l}\text { Provide family with time and appropriate privacy to complete rituals } \\
\text { Clarify with family that death may not occur in the expected timeframe and in some circumstances a child may survive longer term. } \\
\text { Inform family/carers of symptoms and signs that may occur postextubation } \\
\text { Outline management of symptoms that may occur } \\
\text { Ensure provisional plans in place for child's ongoing care } \\
\text { Commence any symptom management medication that may be required around the time of extubation and immediately postextubation }\end{array}$ \\
\hline Postextubation & $\begin{array}{l}\text { Review symptoms and initiate appropriate management } \\
\text { Handover care responsibility to local team (community, hospice, hospital) } \\
\text { Review fluid management plan } \\
\text { Provide access to ongoing care and symptom management support (including } 24 / 7 \text { telephone access) } \\
\text { Ensure Emergency Care Plan (ECP) corresponds to current wishes of parents } \\
\text { Communicate child's location and status along with any ECP changes in writing to local primary care, community, hospital and emergency } \\
\text { services } \\
\text { Provide family with written copy of updated ECP } \\
\text { Provide family with information on who to contact should a healthcare professional not be present at time of death }\end{array}$ \\
\hline Post death & $\begin{array}{l}\text { Monitor that previously planned activities are proceeding: Designated medical practitioner available to complete death certificate Designated } \\
\text { family member takes responsibility for postdeath arrangements Agreed upon bereavement support is initiated Planned for care of child's body } \\
\text { postdeath is carried out }\end{array}$ \\
\hline
\end{tabular}


A prospective study of out-of-hospital extubations including parents' experiences and perspectives is now required.

Acknowledgements Dr Joanna Laddie conducted the review while working as a Specialist Registrar in Paediatric Palliative Medicine, The Louis Dundas Centre for Children's Palliative Care, Great Ormond Street Children's Hospital NHS Foundation Trust. We would like to thank Andrew Dinsdale, Data Manager, The Louis Dundas Centre for Children's Palliative Care, Great Ormond Street Children's Hospital NHS Foundation Trust, for his help with accessing the databases and Dr Richard Langner, (Hon) Senior Research Associate, The Louis Dundas Centre for Children's Palliative Care, University College London, Institute of Child Health, for critical feedback on earlier drafts.

Contributors All authors were responsible for conception and design of the review paper. JL developed the data collection instrument, collected and analysed the data. $F C, J L$ and JB provided interpretation of the data. $J L$ and PK drafted the article. FC supervised the project throughout. FC, JB, JL, PK and MB-L reviewed and revised the article critically for important intellectual content. All authors revised the article and provided final approval of content.

\section{Competing interests None.}

Ethics approval The project was registered with the clinical audit department of the Tertiary trust. Registration number 776. Clinical Audit Department Great Ormond Street Children's Hospital NHS Foundation Trust.

Provenance and peer review Not commissioned; externally peer reviewed.

Open Access This is an Open Access article distributed in accordance with the Creative Commons Attribution Non Commercial (CC BY-NC 3.0) license, which permits others to distribute, remix, adapt, build upon this work non-commercially, and license their derivative works on different terms, provided the original work is properly cited and the use is non-commercial. See: http://creativecommons.org/ licenses/by-nc/3.0/

\section{REFERENCES}

1 Paediatric Intensive Care Society Multidisciplinary Working Group. Standards for the care of critically ill children. 4th edn. London: Paediatric Intensive Care Society, 2010.

2 Draper E, Lamming C, McKinney P, et al. Annual Report of the Paediatric Intensive Care Audit Network January 2007-December 2009. PICA Net. http://www.picanet. org.uk/Documents/General/Annual\%20Report\%202010/2010\%20PICANet\% 20Annual\%20Report.pdf

3 Yates $\mathrm{Y}$, Festa M, Gillis J, et al. Outcome of children with neuromuscular disease admitted to paediatric intensive care. Arch Dis Child 2004;89:170-5.

4 Singer K, Subbaiah P, Hutchinson R, et al. Clinical course of sepsis in children with acute leukemia admitted to the pediatric intensive care unit. Pediatr Crit Care Med 2011;12:649-54

5 Sands $\mathrm{R}$, Manning JC, Vyas $\mathrm{H}$, et al. Characteristics of deaths in paediatric intensive care: a 10-year study. Nurs Crit Care 2009;14:235-40.

6 Ramnarayan P, Craig F, Petros A, et al. Characteristics of deaths occurring in hospitalised children: changing trends. J Med Ethics 2007;33:255-60.

7 Garros D, Rosychuk R, Cox P. Circumstances surrounding end of life in a pediatric intensive care unit. Pediatrics 2003;112:e371.

8 Inwald D. The best interests test at the end of life on PICU: a plea for a family centred approach. Arch Dis Child 2008:93:248-50.

9 Royal Collage of Paediatrics and child health. Witholding or withdrawing life sustaining treatment in children: a framework for practice. 2nd edn. RCPCH publications, 2004.

10 Oberender F, Tibballs J. Withdrawal of life-support in paediatric intensive care-a study of time intervals between discussion, decision and death. BMC Pediatr 2011;11:39. http://www.biomedcentral.com/1471-2431/11/39

11 Burns JP, Mitchell C, Outwater K, et al. End of life care in the pediatric intensive care unit after forgoing life sustaining care. Crit Care Med 2000;28:3060-6.

12 Williams C, Cairnie J, Fines V, et al. Construction of a parent-derived questionnaire to measure end-of-life care after withdrawal of life-sustaining treatment in the neonatal intensive care unit. Pediatrics 2009;123:e87.
13 McGraw SA, Truog RD, Solomon MZ, et al. I was still able to be her mom-parenting at the end of life in the paediatric intensive care unit. Pediatr Crit Care Med 2012:13:1-7.

14 Moore P, Kerridge I, Gillis J, et al. Withdrawal and limitation of life sustain treatments in a paediatric intensive care unit and review of the literature. J Paediatr Child Health 2008;44:404-8.

15 Needle JS. Home extubation by a pediatric critical care team: providing a compassionate death outside the Pediatric intensive care unit. Pediatr Crit Care Med 2010;11:401-3.

16 Akinsoji Y, McAuley SA, Parkin J. Compassionate extubation in a hospice: strengthening the links between hospice and paediatric intensive care. Arch Dis Child 2010:95:A20.

17 Zwerdling T, Hamann KC, Kon AA. Home pediatric compassionate extubation: bridging intensive and palliative care. Am J Hosp Palliat Care 2006:23:224-8.

18 Longden JV, Mayer A. Family involvement in end-of Life Care in a paediatric intensive care unit. Nur Crit Care 2007:12:181-7.

19 Simpson E, Penrose CV. Compassionate extubations in children at hospice and home. Int J Palliat Nurs 2011;17:164.

20 Cottrell S, Edwards F, Harrop E, et al. A care pathway to support extubations within a children's palliative care framework. 2011. ACT. http://www.act.org.uk/page.asp? section $=406 \&$ sectionTitle $=A+$ care + pathway+to+support+extubation + within + a +children\%27s+palliative+care+framework

21 Meert K, Sarnaik A. Choosing between death at home or in the hospital: Respecting the principle of autonomy. Pediatr Crit Care Med 2010;11:438-9.

22 Johnson M. A parents guide: Making critical care choices for your child. Togeather for Short Lives. 2011.

23 Liben S, Papadatou D, Wolfe J. Paediatric palliative care: challenges and emerging ideas. Lancet 2008;371:852-64.

24 Carter B, Howenstein SM, Gilmer MJ, et al. Circumstances surrounding the deaths of hospitalized children: opportunities for pediatric palliative care. Pediatrics 2004;114:e361-6

25 Midson R, Carter B. Addressing end of life care issues in a tertiary treatment centre: lessons learned from surveying parents' experience. J Child Health Care 2010:14:52-66.

26 Mettauer N, Brierley J. End of life decisions in a tertiary paediatric intensive care centre in the UK. Pediatr Crit Care Med 2007:8:A66.

27 Craig F, Peters M, Rajapakse D, et al. Emerging role of palliative care in paediatric intensive care unit: 3 years' experience of working in partnership. Arch Dis Child 2006;91(Suppl 1):A83-5.

28 Fraser LK, Miller M, Draper ES, et al. Place of death and palliative care following discharge from paediatric intensive care units. Arch Dis Child 2011:96: $1195-8$.

29 Carter B, Craig F. Intensive care units. In: Goldman A, Hain R, Liben S. eds Oxford textbook of palliative care for children. 2nd edn. Oxford University Press, 2012:402-9.

30 Dussel V, Kreicbergs U, Hilden JM, et al. Looking beyond where children die; determinants and effects of planning a childs location of death. J Pain Symptom Mange 2009;37:33-43.

31 Meyer EC, Ritholz MD, Burns JP, et al. Improving the quality of end-of-life care in the pediatric intensive care unit: parents priorities and recommendations. Pediatrics 2006;117:649-57.

32 General Medical Council. Treatment and care towards the end of life; Good practice in decision making. 2010. http://www.gmc-uk.org/static/documents/content/ Treatment_and_care_towards_the_end_of_life_-_English_1011.pdf

33 Carnevale FA, Farrell $C$, Cremer $R$, et al. Struggling to do what is right for the child. J Child Health Care 2012;16:109-23.

34 Neilson S, Clifford C, Kai J. GPs experiences of caring for a child with cancer receiving palliative care at home. Arch Dis Child 2011;96:A81.

35 Gupta N, Harrop E, Lapwood S, et al. Journey from pediatric intensive care to palliative care. J Palliat Med 2013;16:397-401.

36 RCPCH; Royal College of Paediatrics and Child Health guidance on Child Death Review Processes. 2008. 